\title{
DINÂMICA INDUSTRIAL E ASPECTOS INOVATIVOS NO SETOR AUTOMOTIVO
}

\author{
Almir Cléydison Joaquim da Silva ${ }^{1}$ \\ Lucas Henrique Gonçalves ${ }^{2}$ \\ Mônica Aparecida Bortolotti ${ }^{3}$ \\ Walter Tadahiro Shima ${ }^{4}$
}

\section{RESUMO}

O trabalho apresenta uma discussão sobre a indústria automobilística, sua reestruturação produtiva e concorrencial, as inovações recentes e rotas tecnológicas para o setor nos próximos anos, assim como ressalta a importância do financiamento estatal brasileiro, especificamente dos programas e linhas de financiamento do Banco Nacional de Desenvolvimento Econômico e Social (BNDES) para impulso e desenvolvimento de inovações para o setor. A partir de dados da Associação Nacional dos Fabricantes de Veículos Automotores (Anfavea) e da Organisation Internationale des Constructeurs d'Automobiles (OICA), destaca-se a evolução da participação dos mercados emergentes na produção mundial de veículos, estando vinculado a entrada de montadoras internacionais após o processo de abertura comercial, a maior participação do governo com estímulos e financiamentos para o desenvolvimento do setor e a aposta em carros compactos e econômicos. Por outro lado, a concorrência no setor está fortemente associada à inovação, onde este se apresenta como elemento cada vez mais estratégico frente a novas rotas tecnológicas.

Palavras-chaves: Setor automotivo; Inovação; Política Industrial.

\begin{abstract}
The paper presents a discussion on the automotive industry, its productive and competitive restructuring, recent innovations and technological routes for the sector in the coming years, as well as highlighting the importance of the Brazilian state financing, specifically the programs and financing lines of the National Bank for Economic and Social Development (BNDES) to boost and develop innovations for the sector. From the data of the National Association of Automobile Manufacturers (Anfavea) and the International Organization of Constructors of Automobiles (OICA), the evolution of the participation of emerging markets in the world production of vehicles, being linked to the entry of international automakers after the process of commercial opening, the greater participation of the government with stimuli and financing for the development of the sector and the bet on compact and economic cars. On the other hand, competition in the sector is strongly associated with innovation, where innovation presents itself as an increasingly strategic element in the face of new technological routes.
\end{abstract}

Keywords: Automotive industry; Innovation; Industrial Policy.

\section{ÁREA ABEIN: 1 -/ INDÚSTRIA E COMPETITIVIDADE}

JEL: L00; L62.

\footnotetext{
${ }^{1}$ Economista pela UFPB e mestrando em Políticas Públicas na UFPR, almirjoaquim@gmail.com

${ }^{2}$ Bibliotecário pela UDESC e mestrando em Políticas Públicas na UFPR, luc4s.hg@gmail.com

${ }^{3}$ Economista e mestre em Extensão Rural pela UFSM, mestre em Desenvolvimento Regional pela UTFPR e doutoranda em Políticas Públicas pela UFPR, monica_economia@yahoo.com.br

${ }^{4}$ Professor do D/epartamento de Economia e do Programa de Pós-graduação em Políticas Públicas da UFPR, waltershima@ufpr.br
} 


\section{INTRODUÇÃO}

O setor automotivo possui uma importância estratégica na configuração da estrutura industrial brasileira, tanto em função de seu peso na indústria de transformação quanto em seus efeitos na geração de empregos, diretos e indiretos. Soma-se a esses dois elementos a grande capacidade de encadeamento produtivo sobre outros setores econômicos, onde o seu desempenho afeta diretamente a produção de diversos setores da indústria (KIM, 2005; DE NEGRI et al., 2008).

A cadeia produtiva do setor automotivo, que envolve tanto empresas montadoras quanto empresas fornecedoras de peças completas ou partes, as chamadas sistemistas, compõem um setor tradicionalmente oligopolístico. E, por conseguinte, a inovação tem cada vez mais se caracterizado como um elemento determinante do processo competitivo, atrelado à mudanças organizacionais e principalmente tecnológicas.

No que concerne a indústria automobilística internacional, cabem menção a dois importantes movimentos ocorridos em fins dos anos 1960 que auxiliam na compreensão da expansão da participação dos países emergentes na produção mundial de veículos, a saber: i) mudança do paradigma tecnológico setorial e; ii) ingresso em novos mercados geográficos. Ambos os movimentos decorreram em resposta a saturação dos mercados de bens de consumo duráveis, ocasionados da padronização de produção em massa, a chamada crise do paradigma tecno-econômico. Nos países desenvolvidos a forte competição entre empresas, a partir da saturação dos mercados, levou a quedas significativas nos lucros. Atrelado a isso, a indústria automotiva industrial vivenciou forte elevação dos custos de produção com os dois choques nos preços mundiais do petróleo (COSTA; HENKIN, 2016).

As mudanças no paradigma tecnológico compreenderam tanto inovações de produto e processo, quanto técnicas organizacionais. O primeiro foi possível a partir de avanços na microeletrônica, enquanto que o segundo caso decorreu da difusão, ao longo das décadas de 1970 e 1980, da produção enxuta, com a introdução do sistema de administração da produção just-in-time. Por outro lado, a entrada de montadoras de veículos nos mercados emergentes ocorre a partir do processo de globalização com pressões políticas e econômicas para abertura comercial, produtiva e financeira, no início da década de 1990. De acordo com Costa e Henkin (2016, p. 463) a intensificação comercial, de capitais e mercadorias, entre as nações implicou em mudanças estratégicas no comportamento das montadoras de diversos países, levando a um processo de internacionalização da produção de autoveículos, a partir de "um fluxo de investimentos diretos externos para países e regiões em desenvolvimento, onde havia um maior potencial de crescimento do consumo de autoveículos".

A partir da abertura comercial, Costa e Henkin (2016) destacam dois processos distintos, relacionados ao ambiente competitivo, pelo qual o setor automotivo brasileiro passou a enfrentar com a entrada de veículos importados: i) reestruturação produtiva (1989 a 2003) e; ii) consolidação do Brasil como centro consumidor e plataforma regional de produção e distribuição de autoveículos na América do Sul (2004 a 2013). A reestruturação produtiva é marca, de um lado, por um movimento de convergência das estratégias utilizadas entre as empresas subsidiárias instaladas no Brasil com as empresas matrizes instaladas em outros países e, de outro lado, por uma transferência tecnológica envolvendo produtos e processos que contribuiu para uma significativa redução no hiato tecnológico. Vale ressaltar que os investimentos realizados pelas montadoras pressionaram também os fabricantes de automóveis já instalados no país. A partir de 2004, com a melhora da situação da economia brasileira e com diversas estratégias e ações para elevação do poder aquisitivo e de acesso ao crédito, eleva-se a demanda por veículos. Consequentemente, esse cenário posiciona o país enquanto um mercado estratégico com tendências de expansão do consumo e um importante centro de produção regional de autoveículos, especialmente para a América do Sul.

Nesse sentido, o trabalho apresenta uma discussão sobre a indústria automobilística, envolvendo a reestruturação produtiva e concorrencial, as inovações recentes e rotas tecnológicas para o setor automotivo, assim como destaca a importância do financiamento estatal brasileiro, especificamente dos programas e linhas de financiamento do Banco Nacional de Desenvolvimento Econômico e Social (BNDES) para impulso e desenvolvimento de inovações para o setor. Além de uma revisão de literatura sobre o setor automotivo e às políticas industriais brasileiras, analisam-se dados sobre produção de 
autoveículos, para caracterizar e chamar a atenção para a evolução da participação dos mercados emergentes na produção mundial de veículos. Os dados utilizados foram coletados nas bases de dados da Associação Nacional dos Fabricantes de Veículos Automotores (Anfavea) e da Organisation Internationale des Constructeurs d'Automobiles (OICA). Cabe ainda destacar que autoveículos compreende automóveis, veículos comerciais leves, caminhões e ônibus, que embora possuam características próprias e especificidades de mercado são aqui abordados em conjunto devido a aspectos comuns, como bem aborda Costa e Henkin (2016), quanto às estratégias adotadas e às tecnologias.

Além dessa introdução, este trabalho encontra-se estruturado em mais três seções. A segunda apresenta uma revisão teórica envolvendo características da política industrial brasileira, concorrência e inovação. $\mathrm{Na}$ terceira seção procura-se apresentar os principais aspectos observados no setor automobilístico. Para tanto, essa seção encontra-se subdividida em cinco tópicos, a saber: i) cadeia produtiva ampliada do setor automotivo; ii) indústria mundial: reestruturação produtiva e concorrencial; iii) produção mundial de automóveis e participação dos países emergentes; iv) importância do financiamento estatal brasileiro; v) inovações recentes no setor automotivo. Por fim, a quarta seção apresenta as considerações finais.

\section{CONSIDERAÇÕES SOBRE A POLÍTICA INDUSTRIAL BRASILEIRA}

Ao realizar uma sistematização dos debates sobre política industrial brasileira, Furtado (2002) apontando para a necessidade de formulação de uma política industrial, assim como procura mostrar que a política industrial é ineficaz quanto aos resultados e dispendiosa quanto aos custos. Para tanto, baseia-se em trabalhos de Luciano Coutinho e de Edward Amadeo, respectivamente. No que concerne a existência de políticas industriais, Luciano Coutinho apresenta argumentos de que todos os países possuem política industrial, seja através de ações planejadas ou por omissão das mesmas. Enquanto que Edward Amadeo também considera que o Brasil possui uma política industrial, contudo a considera ineficiente e cara. Em síntese, sobre a existência de política industrial, Furtado (2002) aponta três aspectos principais: a) as omissas (projeta trajetórias passadas para o futuro); b) as tópicas (referentes a problemas localizados, agenda setorial ou regional) e; c) as estruturantes (elevada consistência e permanência temporal, com objetivos de longo prazo). Para o caso brasileiro, destaca-se que as políticas industriais assumiram um papel intermediário, ou seja, direcionadas a interesses setoriais ou regionais. Dada essas considerações, os erros de períodos passados apenas poderão ser resolvidos com uma agenda mais moderna e com instrumentos mais consistentes.

No que se refere às necessidades de uma política industrial, destaca-se a insuficiência de estabilização como forma de promover a retomada do crescimento, a exemplo do Plano Real. Sendo que a retomada do crescimento estaria condicionada a um papel mais ativo do Estado em ações e políticas industriais. Chama-se a atenção para as dimensões do conhecimento e da tecnologia enquanto elementos importantes para criação e difusão de importantes setores e para o desenvolvimento de novos instrumentos industriais. Sobre o dilema de oposição entre mercado interno e externo, considera-se que a vulnerabilidade externa atual brasileira só será sanada com políticas de investimento para exportação, estando fortemente ligada a priorização em conhecimento tecnológico para elevar o valor adicionado das exportações. Ou seja, a pauta de exportações deveria ter uma mudança dinâmica e incorporar produtos com maior conteúdo tecnológico (FURTADO, 2002).

A política industrial é também destacada enquanto um importante elemento para reorientação da política macroeconômica e para sustentação da estabilidade, principalmente devido à fragilidade externa e a um regime macroeconômico perverso, atrelado a efeitos em custos de capital (onerando a economia e restringindo projetos de investimento). Furtado (2002) também destaca a importância do BNDES para estímulo da capacidade produtiva industrial e para inclusão da sociedade via geração de emprego e renda.

Em sentido convergente as considerações de Furtado (2002), especialmente sobre a importância de um papel mais ativo do Estado, Mazzucato (2014) apresenta uma discussão centrada no papel que o Estado exerce junto ao estímulo a inovação tecnológica. Inicialmente discorre sobre a percepção dos que defendem a redução da participação do Estado na economia, onde os seguintes pontos são discutidos: a) a 
não intervenção, em que o Estado deveria se concentrar no fornecimento dos serviços básicos; b) dicotomia entre a eficiência do setor público e do setor privado e; c) o crescimento da terceirização, deixando a entender que os serviços fornecidos pelo setor privado são mais eficientes. Com relação à intervenção do Estado, Evans (2004) destaca a importância de observar o tipo de intervenção e não o quanto ele interfere na economia. Com isso, chama a atenção para dois tipos de estruturas do Estado que geram diferentes capacidades de ação: 1) predadores (a maximização de interesses individuais tem precedentes sobre a busca de objetivos coletivos) e; 2) desenvolvimentista (tanto direcionam a transformação industrial quanto são os responsáveis pela condução do desenvolvimento).

Mazzucato (2014) também destaca a questão do poder da ideologia, estando atrelada a capacidade de propagação de histórias falsificadas sobre o tamanho dos gastos do Estado. Como exemplo, cita a crise financeira de 2007, que mesmo tendo sido gerada por endividamento do setor privado, no mercado imobiliário americano, muitas pessoas foram levadas a acreditar que a culpa foi da dívida pública. Sendo assim, chama-se a atenção ao fato de que a quantidade de gastos públicos não seria o problema, mas que a questão central está na escolha e no tipo de gastos, especialmente para setores e áreas que estimulem a pesquisa e o desenvolvimento, assim como em setores de educação e capital humano.

Apesar da proliferação de que o Estado tem falhado em muitas áreas, cabe destacar a sua capacidade de investimento em áreas de risco elevado e que são importantes para estimular a inovação de muitas tecnologias em longo prazo. Quando comparado com o risco privado, essa tendência já não é observada. Algumas experiências históricas recentes indicam para um papel importante que o Estado exerce, tanto na capacidade de assumir riscos quanto na sua capacidade empreendedora e de financiamento de grandes projetos industriais e de inovação para o setor público. Portanto, Mazzucato (2014) destaca que o Estado precisa compreender seu importante papel e investimentos tanto para não continuar preso a grupos de interesse e lobistas quanto para cobrar maior participação de investimentos privados em inovações.

É importante ressaltar que as políticas inovativas e tecnológicas tem, cada vez mais, ganhado espaço e destaque na agenda de desenvolvimento industrial em países desenvolvidos e em desenvolvimento. Por conseguinte, a ênfase em processos de inovação indica tanto para seu caráter interativo quanto para a necessidade de um fluxo contínuo de conhecimento entre empresas e instituições de pesquisa e de apoio. Por outro lado, essa interação corrobora com a amplitude do processo inovativo, que por sua vez extrapola as atividades de P\&D (CASSIOLATO, 2003).

Ao apresentar uma discussão centrada na compreensão das estruturas e do papel exercido pelo Estado, tanto na relação com a sociedade quanto na contribuição para o desenvolvimento, Evans (2004) admite certa complexidade quanto a definição e análise do Estado, contudo destaca que entre seus papeis clássicos estão as guerras estabelecidas e a garantia da ordem interna. Enquanto que no mundo contemporâneo, o fomento as transformações sociais e ao bem-estar social também tem sido aspectos cada vez mais crescentes, ou seja, a responsabilidade pela transformação econômica.

Promover o bem-estar social tem sido cada vez mais associado à busca pelo crescimento econômico da capacidade produtiva. Com isso, Evans (2004) também chama a atenção para a forma de inserção dos países no processo de divisão internacional do trabalho, onde o êxito da transformação econômica dependerá do contexto global. Ou seja, o processo de comercialização internacional, focado em produtos industriais ou primários, tem forte reflexo sobre as políticas internas e de bem-estar social.

Uma questão importante a destacar diz respeito ao processo de divisão internacional do trabalho que condicionava os países periféricos a fornecer produtos primários e não processados para a expansão dos países centrais, em contrapartida a possíveis vantagens comparativas de termos de troca. Portanto, romper o esquema da divisão internacional do trabalho seria uma condição para alcançar melhores níveis de desenvolvimento. Contudo, a teoria das vantagens comparativas é contrária a essa perspectiva, caso os países não tenham potencialidades naturais em determinados setores (EVANS, 2004).

Por outro lado, Nelson e Winter (1997) apresentam uma discussão sobre modelos alternativos para verificar a crescente concentração de empresas em ramos ou setores de atividade econômica, bem como questões relacionadas à entrada e a barreiras. O modelo proposto e explorado pelos autores baseia-se em uma visão da natureza da concorrência schumpeteriana, a partir de elementos e forças que geram ou limitam o crescimento da concentração de firmas. Um elemento causal e básico destacado refere-se as 
"inovações bem-sucedidas", as quais podem gerar ganhos de lucratividades e, consequentemente, estimular o crescimento de estruturas setoriais fortemente concentradas (NELSON; WINTER, 1997).

O modelo estocástico desenvolvido por Nelson e Winter, que visa analisar as formas dinâmicas que afetam a concentração em concorrência schumpeteriana, mesmo estando associada a "lei de Gibrat", para análise de distribuição e tamanho das firmas, vincula-se a uma perspectiva de correlação serial, na medida em que considera-se a probabilidade de que uma firma possuidora de uma tecnologia em média melhor, amanhã pode ou não possuí-la (NELSON; WINTER, 1997).

Para desenvolvimento e teste do modelo, chamado de "projeto experimental", os autores formulam algumas hipóteses, das quais se destacam: a) ramo de atividade inicialmente desconcentrado; b) firmas atuam em um processo de concorrência schumpeteriano; c) possuem as mesmas políticas de P\&D e; d) política definida em termos do dispêndio em inovação e em imitação por unidade de capital. Pela lógica de concentração adotada pelo modelo, e enfatizado por Nelson e Winter (1997, p. 447), "torna plausível que quanto mais rápido for o ritmo de expansão das oportunidades tecnológicas ao longo do tempo, tanto maior será a propensão de o ramo tornar-se concentrado". Ou seja, as inovações bem-sucedidas em P\&D elevam a produtividade e as vantagens da firma, que estimula positivamente sua lucratividade e taxa de crescimento, podendo levar a um aumento da concentração. Cabe ressaltar que a vantagem de $\mathrm{P} \& \mathrm{D}$ da firma será duradoura se for de difícil imitação pelas outras firmas não inovadoras, constituindo-se em um importante elemento que influencia o crescimento da concentração de um ramo ao longo do tempo (NELSON; WINTER, 1997).

Voltando-se para as políticas industriais brasileiras, verifica-se que as primeiras ações estatais direcionadas para o setor industrial ocorreram com as políticas de defesa do café e do consequente processo de substituição de importações no governo de Getúlio Vargas (1930-1945). A defesa do café, através da compra de excedentes e de sua consequente destruição por parte do governo, visava amenizar a crise de superprodução do setor nos anos de 1930. Essas incipientes e implícitas políticas industriais também buscavam equilibrar os preços do produto no cenário internacional, contudo, observou-se um agravamento no desequilíbrio externo, com redução do coeficiente de importação (FURTADO, 2005).

De acordo com Furtado (2005), Coronel, Azevedo e Campos (2014) a demanda interna vai aos poucos assumindo importância, especialmente devido ao aumento nos preços importados. Nesse contexto, ocorre uma expansão do setor fabril, contanto com capitais vindos de outros setores e de uma capacidade já instalada. Esse cenário marca o processo de substituição de importações, a partir do aparecimento das primeiras empresas destinadas a esse fim. Durante a gestão de Getúlio Vargas foram criadas também algumas instituições fundamentais para estímulo da indústria nascente, é o caso do Banco de Desenvolvimento Econômico e da Comissão de Desenvolvimento Industrial.

O Plano de Metas no governo de Juscelino Kubitschek (1956-1961) apresentou prioridade em metas de transporte, energia, alimentação, indústria de base, educação e na construção da capital do Brasil. Com o Plano de Metas foram observados importantes avanços no setor industrial, principalmente em decorrência de uma maior interação entre o setor público e o capital privado nacional e posteriormente com estímulos para o investimento direto estrangeiro. Este último sendo viabilizado em decorrência da instrução 113 da Superintendência da Moeda e do Crédito (SUMOC), criada ainda no governo de Café Filho, em 1957. Dentre outros elementos, a instrução 113 da SUMOC previa a possibilidade de importação de máquinas e equipamentos sem cobertura cambial, constituindo-se como fundamentais para o processo de expansão e modernização do setor industrial interno (CAPUTO, MELO, 2009; LACERDA et al., 2010; CORONEL; AZEVEDO; CAMPOS, 2014).

Com o II Plano Nacional de Desenvolvimento (II PND), o Governo Ernesto Geisel (1974-1979), através de uma política de financiamento e subsídios, procurou estimular a adoção de tecnologias mais sofisticadas na produção da indústria de bens de capital nacional. A configuração dos choques do petróleo no cenário internacional impactou negativamente as economias mundiais. No Brasil, a crise do petróleo tanto contribuiu para o não alcance das metas previstas no II PND quanto para o agravamento do cenário problemático interno, com dimensões preocupantes ao longo da década de 1980, principalmente devido ao crescimento da dívida externa e do crescente descontrole da inflação (LACERDA et al., 2010).

O contexto instável que se configurava no ambiente interno e externo condiciona uma guinada à adoção de medidas neoliberais, sendo impulsionada nas economias em desenvolvimento pela adoção de 
um conjunto de dez medidas macroeconômicas do chamado Consenso de Washington, a saber: disciplina fiscal, redução dos gastos públicos, abertura comercial, reforma tributária, privatizações, desregulamentação de leis trabalhistas e econômicas, investimento estrangeiro direto sem restrições, juros de mercado, câmbio de mercado e direito à propriedade intelectual. Boa parte dessas medidas foi incorporada durante a década de 1990 no Brasil, especialmente com os governos de Fernando Collor (1990-1992) e Fernando Henrique Cardoso (1995-2002) (BATISTA JÚNIOR, 1994). As medidas neoliberais adotadas, principalmente a maior abertura econômica no início da década, tanto sinalizaram o encerramento da fase substitutiva de importações quanto indicaram para a intensificação competitiva global. A esse respeito, Cassiolato (2003, p. 321) considera que "com a abertura, a indústria tem sido submetida a uma crescente exposição ao ambiente competitivo internacional. No entanto, esta mudança de orientação não se inseriu dentro de uma política industrial e tecnológica que articulasse tais objetivos com outros compensatórios ou complementares". Para tanto, o resultado é a queda das exportações brasileiras frente ao crescimento do comércio mundial, além disso, argumenta que

O quadro brasileiro, por sua vez, associa uma situação de reduzidos esforços inovativos, com baixos níveis de gastos privados em P\&D e falta de cooperação entre as instituições de pesquisa e o setor produtivo, numa situação em que a estabilização da economia impede medidas como os necessários aumentos de gastos públicos em ciência e tecnologia. Assim, a superação da atual fragilidade tecnológica nacional requer reverter a tendência de retração das atividades de inovação ao nível do sistema e induzir uma mudança fundamental nas estratégias industriais, buscando o aprendizado e a capacitação para inovação de forma persistente e cumulativa (CASSIOLATO, 2003, p. 322).

Diante desse cenário e das estratégias adotadas durante a década de 1990, a própria conjuntura globalizada passa a exigir, no início dos anos 2000, um maior planejamento das políticas industriais, de forma coordenada e sistemática. Para tanto, "necessitaria de uma reestruturação profunda e redefinição do papel das principais instituições responsáveis pela implementação das políticas, assim como dos instrumentos utilizados" (CASSIOLATO, 2003, p. 322). Nesse sentido, a competitividade industrial torna-se elemento dependente de um novo contexto de vantagens comparativas, estando associadas tanto a recursos de conhecimento e capacitação quanto a estruturas institucionais que viabilizem aspectos inovativos organizacionais e tecnológicos.

A conjuntura econômica interna e externa favoráveis, no início do governo Lula (2003-2010), contribuíram para formulação de uma estratégia coordenada de desenvolvimento industrial que resultou na Política Industrial, Tecnológica e de Comércio Exterior (PITCE). A PITCE prevaleceu entre os anos de 2004 a 2007, estando direcionada a quatro eixos principais, a saber: i) inovação e desenvolvimento tecnológico; ii) inserção externa; iii) modernização industrial e ambiente institucional e; iv) elevação da capacidade produtiva (CORONEL, AZEVEDO, CAMPOS, 2014).

Dentre os setores com foco estratégico da PITCE destacam-se os semicondutores, fármacos, software e bens de capital, tendo a inovação como um importante elemento para fomento industrial via incetivos fiscais. De forma geral, a PITCE procurou estabelecer uma interligação maior entre a política industrial com as política de estímulo ao comércio externo. Muito embora as políticas industriais formuladas pelo governo federal estivessem direcionadas para às políticas tecnológicas, questionamentos centraram-se no caráter tímido de seus mecanismos. Este é o caso de Cassiolato (2003, p. 323), ao destacar que "continua o equívoco do governo anterior de enfatizar incentivos fiscais a P\&D como principal estímulo à inovação no setor produtivo. Estes que já são permitidos no Brasil há muito tempo têm se mostrado, como se sabe, inoperante". Em 2008 foi lançado a Política de Desenvolvimento Produtivo (PDP), que dentre os seus objetivos estavam a elevação da competitividade e de geração de trabalho, via estímulo a capacidade inovativa. Vale destacar que essa nova política industrial expandiu consideravelmente sua abrangência em termos de setores, passando a considerar vinte e quatro setores da indústria brasileira, a exemplo da agroindústria, bens de capital, complexo automotivo, indústria naval e cabotagem, nanotecnologia, siderurgia, tecnologia da informação, petróleo, gás, petroquímica e dentre outros. Por conseguinte, parte das metas do PDP não foram atingidas, especialmente, pela abrangência da política (MATTOS, 2013; CORONEL; AZEVEDO; CAMPOS, 2014; BRASIL, 2016; BNDES, 2016). 
A partir de 2011, com o governo de Dilma Rousseff (2011-2016) a política industrial é pautada pelo Plano Brasil Maior (PBM), o qual buscou traçar estratégias tanto em dimensões setoriais quanto sistêmicas. Nas dimensões setoriais, o PBM reduziu de vinte e quatro para dezenove setores priorizados, quando comparado ao PDP. Enquanto nas dimensões sistêmicas, procurou meios de estímulo e incentivo aos investimentos, à inovação, ao comércio externo, a competitividade, qualificação profissional e dentre outros. Já no primeiro semestre de 2016, foi lançado uma nova política industrial, o Programa Brasil Mais Produtivo, que além de sinalizar a continuidade dos planos implementados nos anos anteriores, apresentava como foco de ação a elevação da produtividade de empresas industriais (BRASIL, 2016; BNDES, 2016).

Por fim, chama-se a atenção para a importância da inovação enquanto estratégia e eixo central de elevação da competitividade e da consequente melhoria do setor produtivo brasileiro. Para tanto, isso exige tanto reestruturações no âmbito estatal quanto uma maior integração das cadeias produtivas. Nesse sentido, Cassiolato (2003, p. 324) enfatiza que "fica claro que uma implementação deste tipo requer importantes reestruturações institucional e organizacional do aparelho de Estado no sentido de capacitá-lo a pôr em prática essas novas políticas".

\section{ASPECTOS E CARACTERÍSTICAS OBSERVADAS NO SETOR AUTOMOBILÍSTICO}

\subsection{Cadeia produtiva ampliada do setor automotivo}

De acordo com Carvalho (2008), a indústria automobilística envolve atividades complexas relacionadas a processos produtivos e ao próprio conhecimento tecnológico e organizacional, que também implica em sua interação com diversos fornecedores em uma cadeia produtiva. A esse respeito, De Negri et al. (2008) e Bahia; Domingues (2010), chamam a atenção para a configuração da cadeia produtiva ampliada do setor automotivo. Por meio da figura 1, observa-se a interação dos setores dentro da cadeia automotiva, onde as setas indicam os fluxos monetários que ocorrem entre os setores de origem e de destino, ou seja, os vendedores e compradores. Observa-se que os setores produtivos externos a caixa azul (aços e derivados, material eletrônico, máquinas e equipamentos, produtos de metal e artigos de borracha e plástico) apresentam forte ligação no fornecimento aos subsetores automotivos. Cabe ainda destacar a importância do fornecimento de aço e derivados para todos os subsetores da indústria automobilística, em especial para o fluxo de autopeças (peças e acessórios). Este, por sua vez, configura-se como um importante fornecedor para os elos finais da cadeia automotiva (automóveis, caminhonetas e utilitários, bem como caminhões e ônibus).

Por meio dos elos e fluxos observados na figura 1, e mais especificamente os que ocorrem dentro da caixa azul, fica evidente o encadeamento produtivo do setor automotivo com outros setores industriais. É também por meio desse encadeamento intersetorial que se deve direcionar a atenção para a observação da capacidade de inovar, seja de forma concentrada nas empresas líderes, seja a partir da interação entre montadoras de veículos e fornecedores de insumos.

A integração entre empresas fornecedoras, as chamadas sistemistas, junto às empresas montadoras ocorre a partir de quatro níveis de fornecimento (tier). No primeiro nível (tier 1) encontram-se as empresas sistemistas que fornecem peças completas diretamente para as montadoras. Em geral, são grandes empresas multinacionais que assumem custos de projetos, o desenvolvimento de produtos e o gerenciamento dos suprimentos de peças, e, por conseguinte encontram-se integradas às montadoras ou instaladas em suas proximidades. No segundo nível de sistemistas (tier 2) encontram-se as empresas que cooperam com o fornecimento de materiais e peças isoladas para as sistemistas de nível 1. Processo similar ocorre com as sistemistas de terceiro (tier 3) e quarto (tier 4) níveis, fornecendo respectivamente para as sistemistas de nível 2 e 3 (FREEMAN; SOETE, 2008; CASOTTI; GOLDENSTEIN, 2008). 
Figura 1 - Cadeia produtiva ampliada do setor automotivo

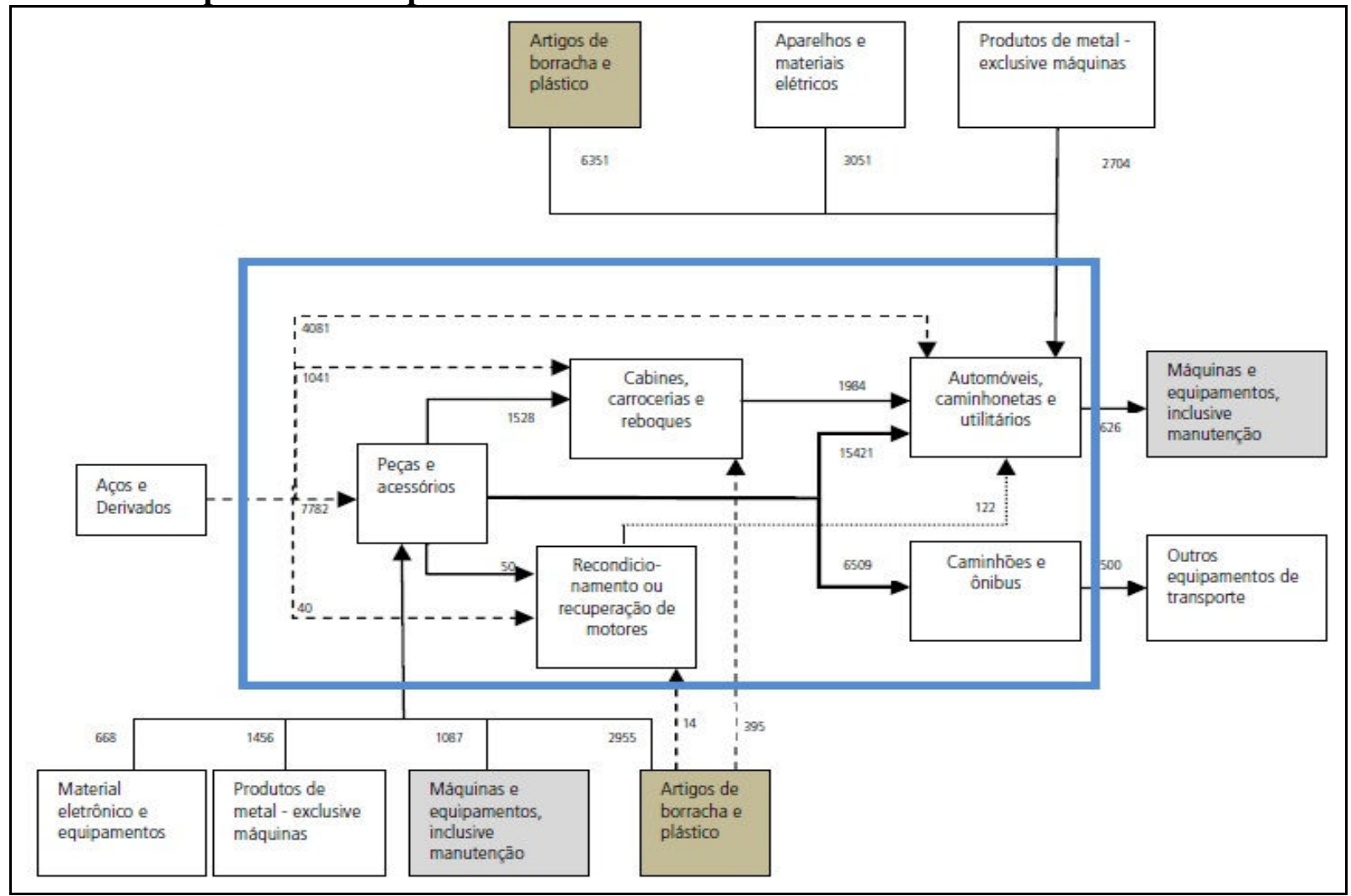

Fonte: De Negri et al. (2008) e Bahia; Domingues (2010).

Cabe ainda destacar que a cadeia automotiva configura-se como uma das mais importantes na economia brasileira, estando relacionada ao fato de que seu desempenho pode afetar, direta e indiretamente, diversos setores econômicos. Portanto, é uma cadeia determinante para o crescimento do produto interno bruto do país, corroborado pelo fato de que no pós década de 1960, os ciclos da economia brasileira iniciam-se e tem como foco os setores de bens de consumo duráveis, especialmente nas estratégias de desenvolvimento da cadeia automotiva no país. "Esta é uma característica da estrutura econômica brasileira, o que torna fortemente relevante entender a dinâmica de inovação na cadeia automobilística, pois ela tem um efeito significativo sobre a difusão de progresso técnico no Brasil" (BAHIA; DOMINGUES, 2010, p.11).

A partir dessas considerações sobre a importância e peso da cadeia automotiva para a economia brasileira, cabe fazer uma breve menção ao processo de reestruturação pela qual o setor passou nas últimas décadas.

\subsection{Indústria Mundial: reestruturação produtiva e concorrencial}

A indústria automobilística tem apresentado relevância significativa para o desenvolvimento das economias mundiais, tanto em decorrência de seu peso e importância na economia quanto pelas iniciativas inovadoras em desenvolvimento de modelos de gestão fabril e de novas tecnologias. Contribuindo, portanto, para o desenvolvimento da indústria moderna (CASOTTI; GOLDENSTEIN, 2008).

Em cenário mundial, destaca-se a passagem da produção artesanal (no século XIX) para a produção em massa (no início do século XX). Essa transição foi possível graças a Henry Ford, fundador da Ford Motor Company, e sua incorporação de inovações básicas na linha de montagem da Ford, ou seja, trata-se de inovações organizacionais, técnicas e sociais que possibilitaram a redução dos custos e do preço do modelo desenvolvido no período, o Modelo T. O processo produtivo e as linhas de montagem passaram a ser organizadas fundamentalmente a partir de esteiras rolantes (FREEMAN, SOETE, 2008; CASOTTI; 
GOLDENSTEIN, 2008). Soma-se a isso, a dominação do motor a combustão interna nos anos 1920 , frente à máquina a vapor e ao motor elétrico, assim como o desenvolvimento da intercambialidade de peças. De acordo com Freeman e Soete (2008) os ganhos de escala na produção decorrentes de custos e preços decrescentes provocaram uma verdadeira revolução na economia e nas técnicas de administração, induzindo ao sistema de produção em massa. Neste contexto, o fordismo surge vinculado à alta mecanização da produção, padronização de processos e produtos, linhas de montagens móveis, altos salários (para combater a alta rotatividade), elevada produtividade e preços baixos dos produtos. Esses elementos foram viabilizados a partir de um maior processo de divisão e especialização de tarefas, sendo compreendidos como "[...] estratégias fundamentais para permitir o sucesso desse novo modelo, que inovava ao conseguir uma produção em larga escala a menores custos e prazos" (CASOTTI; GOLDENSTEIN, 2008, p. 149).

O sistema de produção em massa também foi acompanhado por problemas relacionados a peças defeituosas. Este foi um elemento central pelo qual os produtores japoneses, no pós Segunda Guerra Mundial, afrontaram o sistema fordista via redução de subsistemas e peças defeituosas. A utilização e experiências com a engenharia reversa também contribuiu para o foco na alta qualidade dos produtos e da tecnologia japonesa. Mesmo que as firmas japonesas não tenham realizado grandes inovações radicais nos produtos, suas inovações incrementais e a capacidade de redesenhar projetos e processos foram fatores chaves para a vantagem competitiva que alcançaram, especialmente vinculado aos ganhos de produtividade e de qualidade. Com o surgimento do sistema de produção enxuta da Toyota introduziramse novas práticas para produção de automóveis: redução de desperdícios, mais responsabilidades aos trabalhadores na linha de produção, transferência de responsabilidades para equipes de produção, relação de proximidade com os fornecedores (por meio do chamado just-in-time, uma nova configuração de organização e coordenação dos fluxos de fornecimento de peças, eliminando especialmente os estoques e dinamizando o tempo), assim como o estímulo a discussão sobre os processos e produtos entre engenheiros e trabalhadores (FREEMAN, SOETE, 2008). Deste modo, o sistema intensivo em capital e tecnologia ganha espaço em detrimento do sistema intensivo em mão de obra, onde a qualidade torna-se um importante elemento de diferenciação, especialmente para inserção e concorrência no mercado internacional (CASOTTI, GOLDENSTEIN, 2008).

Cabe chamar a atenção para as mudanças significativas que o sistema just-in-time proporcionou no relacionamento entre empresas montadoras de veículos e as empresas sistemistas. Por um lado, o sistema estabelece uma maior dependência às empresas fornecedoras, um maior compartilhamento de riscos e uma comunicação mais complexa e constante entre montadoras e fornecedores, por outro lado exige das empresas fornecedoras uma maior qualidade nos componentes fornecidos e uma adequação aos novos projetos e inovações das montadoras.

A propagação de inovações produtivas e gerenciais oriundas do setor automobilístico para os demais setores industriais foi induzida, especialmente, pela introdução dos veículos japoneses no mercado internacional. Após a difusão desse segundo modelo de gestão, adotado por diversas empresas em nível mundial, um novo modelo de organização tem-se configurado no setor automotivo, o chamado consórcio modular. Esse modelo consiste em "trazer para dentro da fábrica os fornecedores e delegar a eles a montagem dos veículos, permitindo que as montadoras concentrem seus esforços nas estratégias de marketing e vendas e, sobretudo, na pesquisa, desenvolvimento e inovação, que são os fatores mais críticos para o sucesso da indústria moderna" (CASOTTI, GOLDENSTEIN, 2008, p. 150). A introdução desse modelo ocorreu em 1996 pela fábrica da Volkswagen no Brasil, em Resende-RJ, e tem possibilitado redução de custos devido à padronização de sistemas e ao compartilhamento de infraestrutura entre a montadora e os fornecedores. Ainda que o consórcio modular não tenha sido difundido entre outras indústrias automotivas no Brasil (MEZA, 2003), a configuração produtiva do mesmo já foi utilizada por empresas de outros setores, como é o caso da Embraer. Nesse sentido, Casotti e Goldenstein (2008, p.151) apontam para a tendência desse modelo de gestão e organização produtiva tornar-se referência para complexos industriais organizados a partir de cadeias de fornecimento, "reafirmando o status do setor automotivo como berço de inovações produtivas e gerenciais para a indústria". 


\subsection{Produção mundial de automóveis e participação de países emergentes}

Nos últimos anos os países emergentes têm ampliado consideravelmente sua participação na produção mundial de automóveis, exemplo disso foi o crescimento de $157 \%$ entre 2002 e 2016, conforme tabela 1. Destaque especial é atribuído a forte inserção e participação da produção de automóveis da China, Índia e países do Leste Europeu que apresentam taxas de crescimento, para o período em análise, de $756 \%, 402 \%$ e $192 \%$, respectivamente. O bom desempenho dos países emergentes está relacionado ao padrão de consumo direcionado para a produção de carros baratos. Outro elemento que também corrobora para esses resultados tem sido a penetração de montadoras nessas economias, visando especialmente o crescimento potencial de seus mercados. Assim sendo, "revelou-se eficaz a estratégia de fechamento de fábricas nas economias desenvolvidas e abertura, nas emergentes. $O$ resultado da relocalização das montadoras foi um aumento consistente da participação dos emergentes na produção mundial de veículos, nos últimos anos" (CASOTTI, GOLDENSTEIN, 2008, p. 158).

Para o caso da China e Índia, acrescenta-se ainda o fato de que esses dois novos players têm cada vez mais ganhado importância em termos de crescimento e participação na produção mundial de veículos. Isso pode ser observado tanto pela atração de importantes volumes de investimentos quanto pelo alcance potencial de seus produtos em nível internacional, contribuindo, consequentemente, com mudanças nos padrões de concorrência mundial. O crescimento acelerado da China foi viabilizado através de uma participação ativa do governo central no âmbito do setor automotivo com instrumentos de apoio às empresas que estavam iniciando suas atividades, especialmente com a utilização de investimentos diretos e a concessão de crédito. Outros aspectos que marcam o caso chinês decorrem da atuação do Estado e municípios como proprietários de montadoras no país, o auxílio técnico de universidades públicas ao desenvolvimento automotivo, assim como o estabelecimento de regulação para entrada de montadoras internacionais no país, a exemplo da forma de joint ventures, cláusulas de transferência tecnológica, limitação da participação estrangeira em 50\% (quando o foco fosse o mercado interno) e $40 \%$ de autopeças deveriam ser adquiridas localmente. O principal destino dos veículos produzidos na China tem sido o mercado interno ${ }^{5}$, especialmente devido o baixo percentual da população com veículos. Nesse contexto, e considerando o baixo custo da mão de obra e o perfil aquisitivo da população que privilegia o custo em detrimento da qualidade e segurança, as montadoras chinesas tem se especializado na produção de carros ultrabaratos que, como bem destacam Casotti e Goldenstein (2008, p. 161), "apesar de ainda pecarem na qualidade e segurança, lançam base para uma nova concepção de 'veículos para o povo': preço até US\$ 5 mil, aparência moderna e potência reduzida".

Em sentindo convergente ao caso da China, a Índia tem apresentado crescimentos significativos na produção de veículos, assim como se tem configurado como um dos maiores mercados consumidores em potencial para o setor automotivo, principalmente devido ao reduzido número de pessoas possuidoras de automóveis. Soma-se a isso, a abundância de mão de obra barata e qualificada que induz a um movimento de investimentos de grandes montadoras para o país. A aposta também tem sido na fabricação de carros compactos e baratos, mas com deficiências em aspectos de qualidade e de segurança que prejudicam a introdução de seus produtos em mercados desenvolvidos (CASOTTI, GOLDENSTEIN, 2008).

Feita essas considerações sobre os aspectos de desempenho dos dois principais players, observa-se que os demais países emergentes, selecionados na tabela 1, seguem uma mesma tendência histórica de ampliação da participação na produção mundial de veículos, embora em dimensões menores. Para o período de 2002 a 2016, destaca-se o crescimento de alguns países do leste europeu, a exemplo de Eslováquia, Romênia, Hungria, República Tcheca e Polônia, com taxas de crescimento simples de 361\%, $352 \%, 334 \%, 202 \%$ e $119 \%$, respectivamente. Ainda que México e Brasil tenham apresentado taxas de crescimentos inferiores, $99 \%$ e $20 \%$ respectivamente, cabe destacar o significativo peso e participação na

\footnotetext{
${ }^{5}$ Vale ressaltar que esforço tem sido feitos para que a produção de veículos chineses entre nos mercados externos, especialmente no norte-americano e europeu. Contudo, as tentativas têm fracassado devido o não cumprimento de normas básicas de segurança. Por outro lado, os principais destinos das exportações chinesas de veículos tem sido África, Oriente Médio, Sudeste Asiático e timidamente para a América do Sul, especialmente com a abertura da economia do Chile para os produtos chineses, podendo indicar perspectivas potenciais para ampliação de seus produtos em outros países do continente (CASOTTI, GOLDENSTEIN, 2008).
} 
produção mundial de veículos, com produções equivalentes a 3,6 milhões de autoveículos no México e 2,16 milhões no Brasil.

Tabela 1 - Produção de Autoveículos em países emergentes selecionados - 2002 a 2016 (Em milhões de unidades)

\begin{tabular}{|c|c|c|c|c|c|c|c|c|c|c|c|c|c|c|c|}
\hline & 2002 & 2003 & 2004 & 2005 & 2006 & 2007 & 2008 & 2009 & 2010 & 2011 & 2012 & 2013 & 2014 & 2015 & 2016 \\
\hline Argentina & 0,16 & 0,17 & 0,26 & 0,32 & 0,43 & 0,54 & 0,60 & 0,51 & 0,72 & 0,83 & 0,76 & 0,79 & 0,62 & 0,53 & 0,47 \\
\hline Brasil & 1,79 & 1,83 & 2,32 & 2,53 & 2,61 & 2,98 & 3,22 & 3,18 & 3,38 & 3,41 & 3,40 & 3,71 & 3,15 & 2,43 & 2,16 \\
\hline China & 3,29 & 4,44 & 5,23 & 5,72 & 7,19 & 8,88 & 9,30 & 13,79 & 18,26 & 18,42 & 19,27 & 22,12 & 23,73 & 24,50 & 28,12 \\
\hline Índia & 0,89 & 1,16 & 1,51 & 1,64 & 2,02 & 2,25 & 2,33 & 2,64 & 3,56 & 3,93 & 4,17 & 3,90 & 3,84 & 4,13 & 4,49 \\
\hline México & 1,80 & 1,58 & 1,58 & 1,68 & 2,05 & 2,10 & 2,17 & 1,56 & 2,34 & 2,68 & 3,00 & 3,05 & 3,37 & 3,57 & 3,60 \\
\hline Rússia & 1,22 & 1,28 & 1,39 & 1,35 & 1,51 & 1,66 & 1,79 & 0,73 & 1,40 & 1,99 & 2,23 & 2,19 & 1,89 & 1,38 & 1,30 \\
\hline Tailândia & 0,58 & 0,74 & 0,93 & 1,12 & 1,19 & 1,29 & 1,39 & 1,00 & 1,64 & 1,46 & 2,43 & 2,46 & 1,88 & 1,92 & 1,94 \\
\hline $\begin{array}{l}\text { Leste } \\
\text { Europeu* }\end{array}$ & 1,39 & 1,49 & 1,84 & 2,17 & 2,71 & 3,44 & 3,69 & 3,12 & 3,15 & 3,51 & 3,52 & 3,57 & 3,79 & 3,99 & 4,04 \\
\hline $\begin{array}{l}\text { República } \\
\text { Tcheca }\end{array}$ & 0,45 & 0,44 & 0,45 & 0,60 & 0,85 & 0,94 & 0,95 & 0,98 & 1,08 & 1,20 & 1,18 & 1,13 & 1,25 & 1,30 & 1,35 \\
\hline Hungria & 0,14 & 0,13 & 0,12 & 0,15 & 0,19 & 0,29 & 0,35 & 0,21 & 0,21 & 0,21 & 0,22 & 0,32 & 0,44 & 0,50 & 0,47 \\
\hline Polônia & 0,31 & 0,32 & 0,60 & 0,61 & 0,71 & 0,79 & 0,95 & 0,88 & 0,87 & 0,84 & 0,65 & 0,59 & 0,59 & 0,66 & 0,68 \\
\hline Romênia & 0,08 & 0,10 & 0,12 & 0,19 & 0,21 & 0,24 & 0,25 & 0,30 & 0,35 & 0,34 & 0,34 & 0,41 & 0,39 & 0,39 & 0,36 \\
\hline Eslováquia & 0,23 & 0,28 & 0,22 & 0,22 & 0,30 & 0,57 & 0,58 & 0,46 & 0,56 & 0,64 & 0,93 & 0,98 & 0,97 & 1,00 & 1,04 \\
\hline Eslovênia & 0,13 & 0,12 & 0,13 & 0,18 & 0,15 & 0,20 & 0,20 & 0,21 & 0,00 & 0,17 & 0,13 & 0,09 & 0,12 & 0,13 & 0,13 \\
\hline Ucrânia & 0,05 & 0,11 & 0,19 & 0,22 & 0,30 & 0,40 & 0,42 & 0,07 & 0,08 & 0,10 & 0,08 & 0,05 & 0,03 & 0,01 & 0,01 \\
\hline $\begin{array}{l}\text { Total } \\
\text { Emergentes }\end{array}$ & 11,13 & 12,69 & 15,05 & 16,54 & 19,71 & 23,14 & 24,48 & 26,53 & 34,46 & 36,22 & 38,80 & 41,80 & 42,27 & 42,45 & 46,12 \\
\hline $\begin{array}{l}\text { Total } \\
\text { Mundial }\end{array}$ & 58,99 & 60,66 & 64,50 & 66,72 & 69,22 & 73,27 & 70,73 & 61,76 & 77,58 & 79,88 & 84,24 & 87,60 & 89,78 & 90,78 & 94,98 \\
\hline $\begin{array}{l}\text { Participação } \\
\text { países } \\
\text { emergentes } \\
\text { na produção } \\
\text { mundial }\end{array}$ & $18,9 \%$ & $20,9 \%$ & $23,3 \%$ & $24,8 \%$ & $28,5 \%$ & $31,6 \%$ & $34,6 \%$ & $43,0 \%$ & $44,4 \%$ & $45,3 \%$ & $46,1 \%$ & $47,7 \%$ & $47,1 \%$ & $46,8 \%$ & $48,6 \%$ \\
\hline $\begin{array}{l}\text { Fonte: Elal } \\
\text { * Países do } \\
\text { Ucrânia), e }\end{array}$ & مار & a. & Uc & 10 & Ia & $(2$ & . & . & 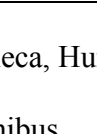 & & & & & & \\
\hline
\end{tabular}

Pelo gráfico 1, abaixo, é possível visualizar a evolução histórica da produção de autoveículos nos países emergentes selecionados. Devido a dispersão dos dados referentes à China, utiliza-se um gráfico com dois eixos. É possível verificar que a partir de 2008 inicia-se um processo de redução da produção de veículos no México, Tailândia, Rússia, países do Leste Europeu, e em menor intensidade Brasil e Argentina, em decorrência dos efeitos da crise financeira desencadeada em 2008. Contudo, China e Índia seguem movimentos inversos, apresentando uma taxa de crescimento na produção de veículos de 2008 para 2009 de $48 \%$ e 13\%, respectivamente. Por outro lado, e em período mais recente, observa-se com mais evidência uma tendência de queda na produção de veículos no Brasil e na Rússia.

Gráfico 1 - Série histórica da produção de Autoveículos em países emergentes selecionados - 2002 a 2016 (Em milhões de unidades) 


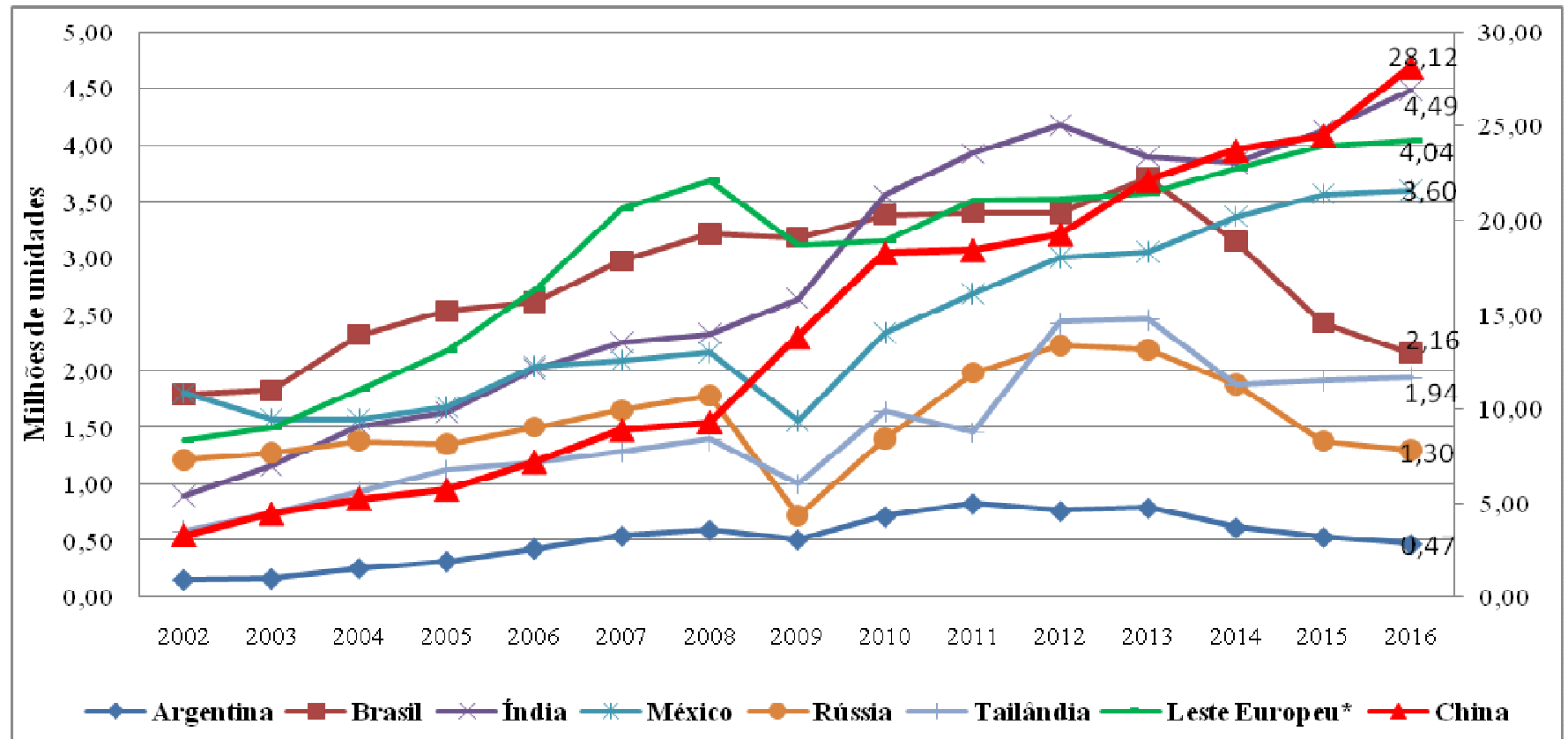

Fonte: Elaboração própria, com base em dados da OICA (2017)

* Países do Leste Europeu produtores de veículos automotores (República Tcheca, Hungria, Polônia, Romênia, Eslováquia, Eslovênia e Ucrânia), exceto Rússia.

Nota 1: Autoveículos compreende automóveis, comerciais leves, caminhões e ônibus.

Nota 2: Gráfico com dois eixos, no eixo primário (Argentina, Brasil, Índia, México, Rússia, Tailândia, Leste Europeu) e no eixo secundário (China).

No que concerne a participação na produção mundial de veículos, a tabela 2 apresenta um ranking dos dez maiores produtores de automóveis. Os dez maiores países concentram uma participação de 79,29\% na produção mundial de veículos, com destaque para China e Estados Unidos que juntos detém uma participação de $42,45 \%$.

Tabela 2 - Ranking e participação na produção mundial de veículos 2016 (Em milhões de unidades)

\begin{tabular}{cccc}
\hline Posição & País & $\begin{array}{c}\text { Unidades } \\
\text { (Em milhões) }\end{array}$ & $\begin{array}{c}\text { Participação na produção } \\
\text { mundial }\end{array}$ \\
\hline $1^{\text {o }}$ & China & 28,12 & $29,61 \%$ \\
$2^{\text {o }}$ & EUA & 12,20 & $12,84 \%$ \\
$3^{\text {o }}$ & Japão & 9,20 & $9,69 \%$ \\
$4^{\text {o }}$ & Alemanha & 6,06 & $6,38 \%$ \\
$5^{\circ}$ & Índia & 4,49 & $4,73 \%$ \\
$6^{\circ}$ & Coréia do Sul & 4,23 & $4,45 \%$ \\
$7^{\text {o }}$ & México & 3,60 & $3,79 \%$ \\
$8^{\text {o }}$ & Espanha & 2,89 & $3,04 \%$ \\
$9^{\circ}$ & Canadá & 2,37 & $2,50 \%$ \\
$1^{\circ}$ & Brasil & 2,16 & $2,27 \%$ \\
\hline \multicolumn{7}{c}{ Total Mundial } & 94,98 & $100,00 \%$ \\
\hline
\end{tabular}

Fonte: Elaboração própria, com base em dados da OICA (2017)

A partir dos dez países melhor posicionados neste ranking de 2016, procurou-se observar e traçar uma série histórica da participação dos mesmos na produção mundial de autoveículos. Por meio do gráfico 2, observa-se os movimentos de reposicionamento da participação dos países na produção mundial ao longo dos anos de 2002 a 2016, ficando mais evidente o caso dos cinco principais players na produção mundial. Em 2002, os Estados Unidos liderava o ranking, seguido do Japão, Alemanha, China, Coréia do Sul, Espanha, Canadá, México, Brasil e a Índia na última colocação, para os países selecionados. Aos poucos os Estados Unidos vai perdendo espaço para a produção japonesa, sendo ambas ultrapassadas pelo forte crescimento da China, especialmente com a crise financeira de 2008. 
Gráfico 2 - Série histórica de participação na produção mundial de autoveículos dos 10 países melhor posicionados no ranking de 2016 (2002-2016)

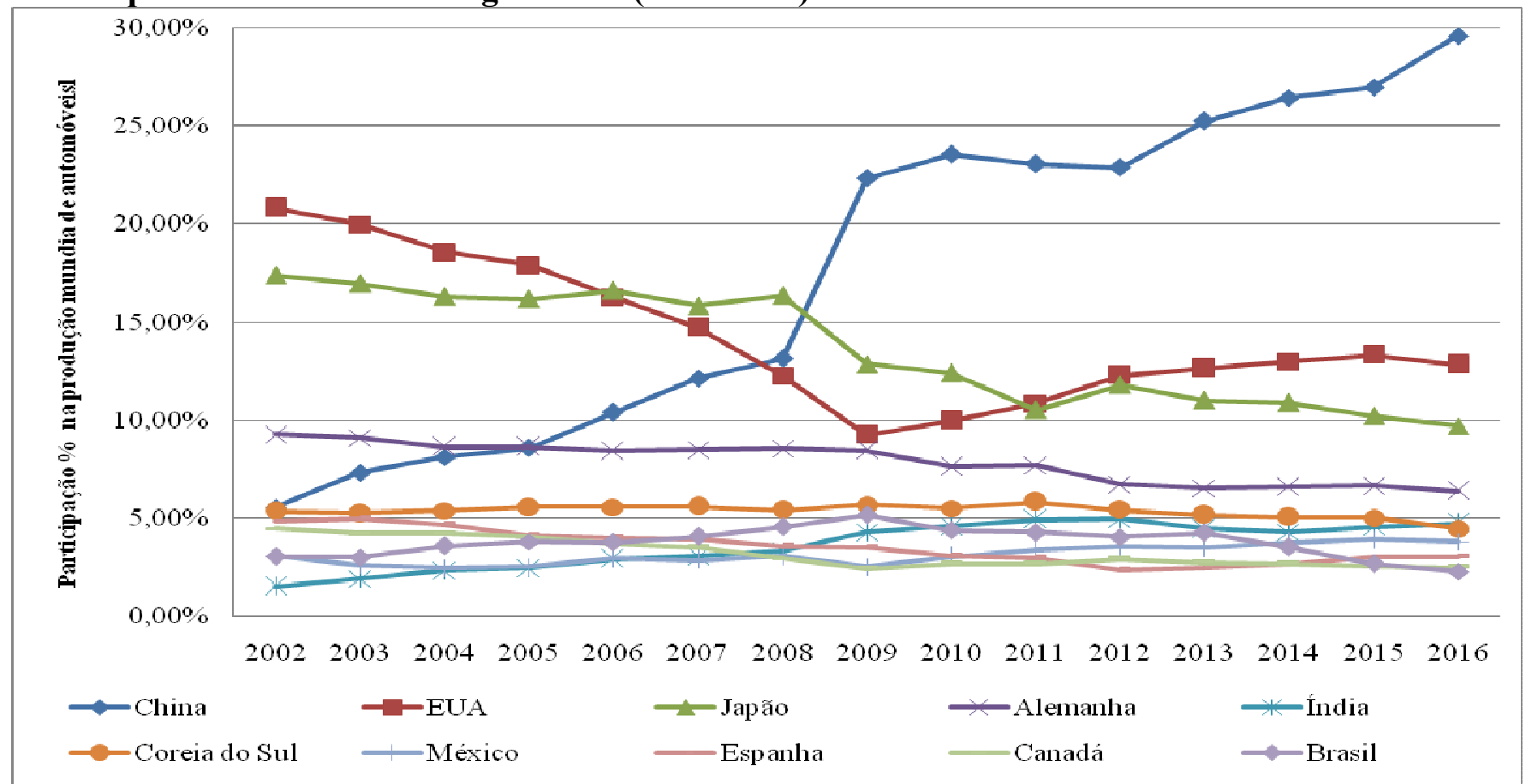

Fonte: Elaboração própria, com base em dados da OICA (2017)

Nota: Autoveículos compreende automóveis, comerciais leves, caminhões e ônibus.

No mesmo sentido, Índia expande sua produção superando o México em 2006, o Canadá em 2007, a Espanha em 2008, o Brasil em 2010 e a Coréia do Sul em 2016. Esse movimento de forte expansão da Índia pode ser observado no gráfico 3, em que devido a dispersão dos dados excluiu-se da comparação a China, Estados Unidos, Japão e Alemanha. Por conseguinte, como indicado na série histórica da gráfico 3, o mercado de produção automotiva da Índia apresenta-se com forte tendência de expansão para os próximos anos.

Gráfico 3 - Série histórica de participação na produção mundial de autoveículos da Índia, Coréia do Sul, México, Espanha, Canadá e Brasil (2002-2016)

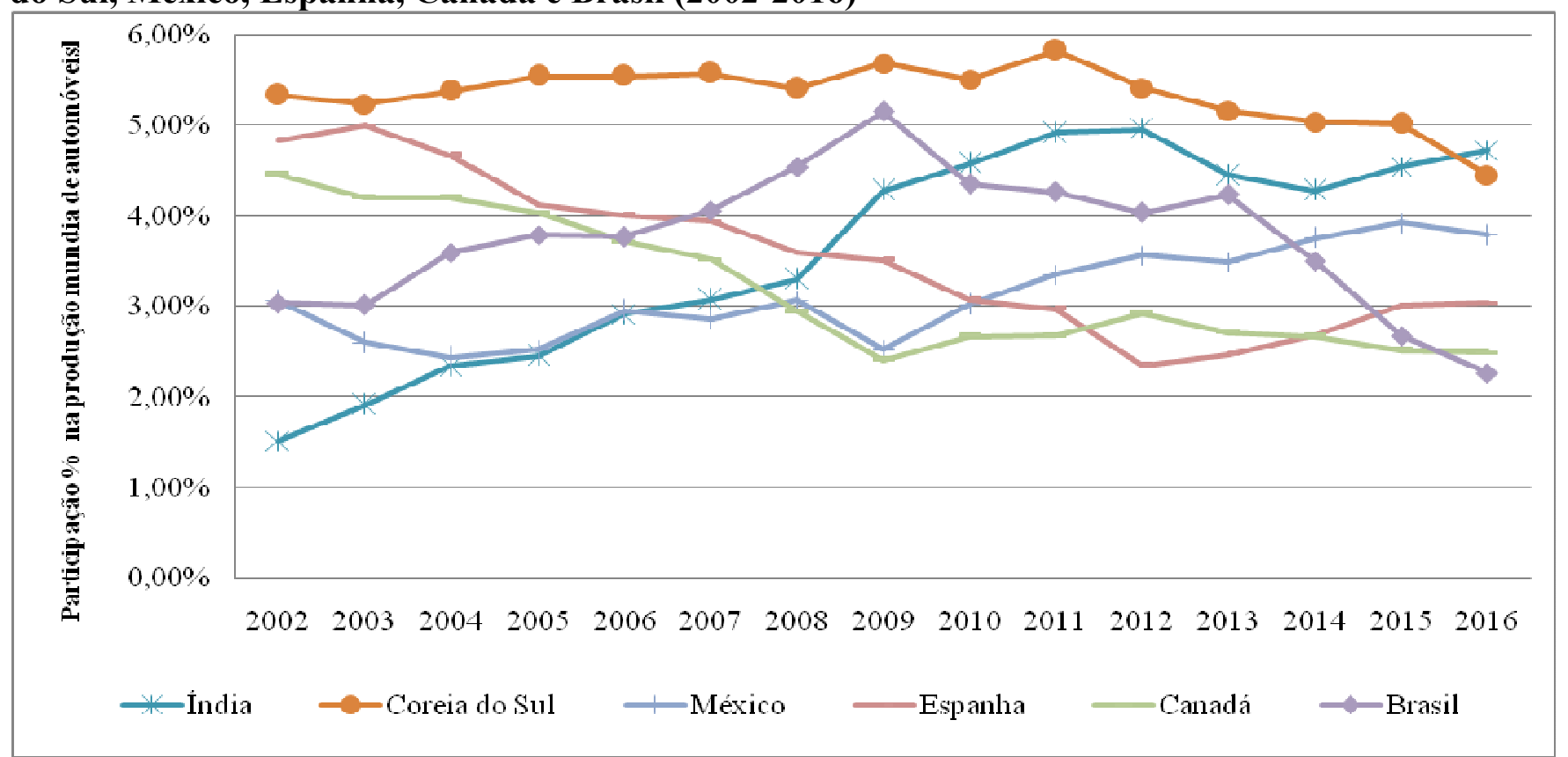

Fonte: Elaboração própria, com base em dados da OICA (2017)

Nota: Autoveículos compreende automóveis, comerciais leves, caminhões e ônibus. 
Direcionando-se para o mercado automotivo brasileiro, verifica-se que a quantidade de veículos com licenciamento nacional anual acompanha a tendência de produção nacional, reafirmando o poder e a participação de seu mercado consumidor. Enquanto que a produção destinada à exportação segue um movimento contrário ao licenciamento importado de veículos. De 2002 a 2008 observou-se um número maior de veículos exportados em detrimento de veículos de procedência estrangeira, entre 2009 e 2015 há um movimento inverso, enquanto que a partir de 2016 a tendência é de expansão de veículos exportados e queda no licenciamento de veículos importado, conforme gráfico 4 abaixo.

Gráfico 4 - Brasil: Produção, exportação e licenciamento (nacional e importado) de autoveículos em milhões de unidades (2002-2016)

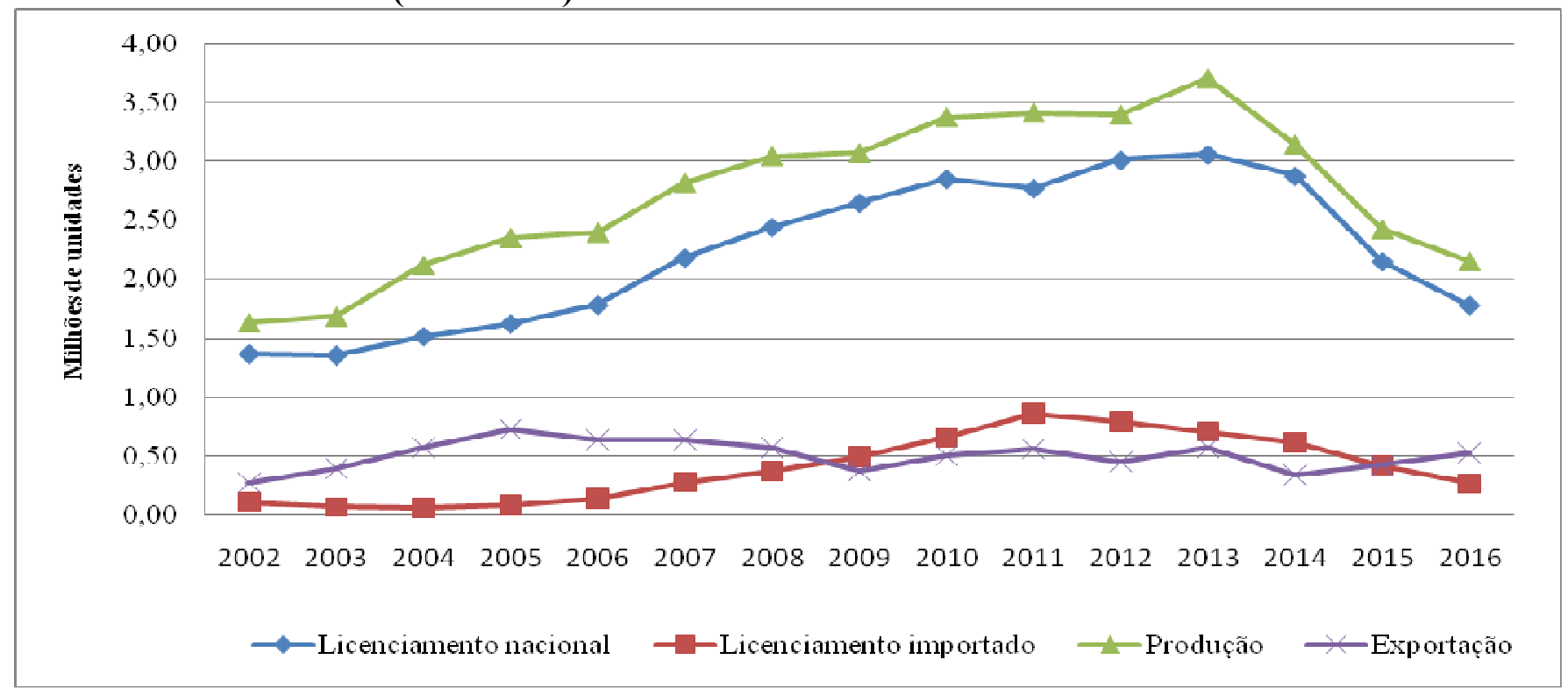

Fonte: elaboração própria com base em dados da Anfavea (2017).

Nota: Autoveículos compreende automóveis, comerciais leves, caminhões e ônibus.

\subsection{Importância do financiamento e atuação estatal no Brasil}

Assim como no caso da China, onde a forte participação do governo central foi fundamental para impulsionar o desenvolvimento do setor automotivo, no cenário brasileiro, Barros e Pedro (2012) destacam a importância da criação do Banco Nacional de Desenvolvimento Econômico e Social (BNDES) para estímulo ao desenvolvimento da indústria automotiva nacional e a priorização de políticas direcionadas para o desenvolvimento de inovações tecnológicas.

A instalação das primeiras indústrias de montagem de veículos no Brasil ocorreu no início do século $\mathrm{XX}^{6}$. Até a primeira metade do mesmo século, as empresas instaladas dedicaram-se a montagem de peças e veículos importados. Foi a partir do segundo governo de Getúlio Vargas (1951-54) e com maior intensidade no Plano de Metas $^{7}$ de Juscelino Kubitschek (1956-61) que se observa os primeiros modelos nacionalizados de veículos, impulsionados tanto pela gradual proibição de importação de autopeças com similar nacional e da importação de veículos completos quanto pelos incentivos governamentais e financiamentos do BNDES. Nos governos subseqüentes, mais especificamente durante o período do milagre econômico, a produção e venda de veículos cresceu substancialmente, contudo, o setor automobilístico deixa de ser prioridade específica na política industrial e passa a ser contemplado

\footnotetext{
${ }^{6}$ As primeiras montadoras multinacionais a se instalarem no Brasil foram: a Ford Motor (1919), General Motors (1925) e Fiat (1928). (CAPUTO; MELO, 2009; BARROS; PEDRO, 2012).

${ }^{7} \mathrm{~A}$ consolidação da indústria automobilística brasileira fazia parte do conjunto de metas do planejamento estratégico do governo de Juscelino Kubitschek, sendo conduzido pelo Grupo Executivo da Indústria Automobilística (GEIA), criado em 1956 (CAPUTO; MELO, 2009; BARROS; PEDRO, 2012).
} 
com políticas gerais do setor industrial (CAPUTO; MELO, 2009; LACERDA, 2010; BARROS; PEDRO, 2012).

A partir dos choques do petróleo e durante a década de 1980 (a chamada década perdida da economia), as vendas de carros sofrem uma queda acentuada, atrelado a restrição de crédito, crise da dívida externa e falta de investimentos, tendo a política economia se direcionado para o controle da inflação. O BNDES desempenhou um papel importante desde sua criação, na década de 1950, até fins da década de 1970, com estímulos e incentivos à comercialização de autopeças no exterior, incentivos a pesquisa e fomento das empresas de capital nacional. Entretanto, "as medidas não estavam inseridas em um planejamento estratégico de longo prazo e, apesar de relevantes, não tiveram continuidade e eram sensíveis às alterações de governo" (BARROS; PEDRO, 2012, p.107).

$\mathrm{Na}$ década de 1990, com a gradual abertura comercial, o setor automotivo volta a ser foco de políticas industriais especificas ${ }^{8}$, sendo motivadas especialmente pelos baixos investimentos no setor durante a década anterior. De acordo com Barros e Pedro (2012, p.107), estes baixos investimentos contribuíram para vários problemas na cadeia automotiva, "[...] com destaque para a reduzida automação e eficiência, a falta de competitividade internacional pela fabricação de modelos defasados tecnologicamente e os altos custos de produção". Sendo assim, tanto a abertura comercial quanto as políticas governamentais proporcionaram mudanças significativas, com progressiva elevação da concorrência, evolução tecnológica (a partir do maior contato com a tecnologia externa), ganhos de produtividade, capacidade produtiva e crescimento do mercado interno.

A partir do início dos anos 2000, observa-se uma mudança expressiva nos financiamentos governamentais para o setor automotivo, que passaram a estimular o desenvolvimento de inovações tecnológicas. Isso induz à adequação que o setor interno deve realizar para a nova agenda da indústria automobilística, necessitando de um redirecionamento das políticas públicas para uma estratégia de planejamento de longo prazo para o setor. Sendo assim, a concorrência passa a pressupor fundamentalmente a inovação como elemento dinâmico e essencial na cadeia automotiva, como bem argumentado por Barros e Pedro (2012) ao apresentar um panorama da nova agenda para o setor, onde

\footnotetext{
Novos conceitos passaram a ser considerados estratégicos e essenciais para a indústria, como o desenvolvimento tecnológico contínuo, investimentos em engenharia automotiva e a adequação dos veículos a requisitos ambientais e de segurança. O desenvolvimento dos veículos passou a ser global, envolvendo engenharia compartilhada entre filiais de diversos países e a matriz. A busca por novas tecnologias passou a ser muito relevante, e a inovação tornou-se prioridade para o desenvolvimento das empresas. A fabricação de veículos híbridos e elétricos, ainda que incipiente, já é realidade em diversos mercados, o que iniciou uma corrida tecnológica entre os principais players do setor. (BARROS; PEDRO, 2012, p. 114-115).
}

Neste contexto, o quadro I apresenta os principais meios de financiamento à inovação do BNDES para a cadeia automotiva, evidenciando o redirecionamento das políticas públicas para o setor a partir dos anos 2000. Diversas alterações são observadas nos programas e linhas de inovação, mas com poucas mudanças em seu conteúdo. Pela análise dos programas e linhas de financiamento à inovação do BNDES, percebe-se que o elemento inovação compreende tanto mudanças incrementais (a exemplo de aprimoramentos em designer, mecânica e desempenho de veículos) quanto mudanças radicais que alteram a trajetória tecnológica dos produtos e/ou processos que, por conseguinte, envolvem elevado risco tecnológico. No curto prazo, as mudanças tecnológicas incrementais são mais utilizadas na produção de veículos, tornando o setor mais competitivo. Contudo, a tendência e o surgimento de novas rotas tecnológicas requerem, cada vez mais, uma articulação e planejamento de longo prazo entre as empresas da cadeia automotiva e as políticas governamentais.

\footnotetext{
${ }^{8}$ Em 1995, por exemplo, foi instituído o Regime Automotivo Brasileiro (Medida Provisória 1024/95), visando: a modernização do setor, elevação do investimento e expansão da competitividade externa. Além disso, “[...] abrangeu incentivos fiscais para as empresas que decidissem se instalar no Brasil e incentivos diferenciados para aquelas que optassem por implantar fábricas nas regiões menos desenvolvidas." (BARROS; PEDRO, 2012, p.108).
} 
Quadro I - Principais meios de financiamento à inovação do BNDES:

\begin{tabular}{|l|l|l|}
\hline $\begin{array}{l}\text { Programas e linhas } \\
\text { de financiamento }\end{array}$ & \multicolumn{1}{|c|}{ Objetivos } & \multicolumn{1}{|c|}{ Observações } \\
\hline $\begin{array}{l}\text { Linha Inovação } \\
\text { PD\&I* }\end{array}$ & $\begin{array}{l}\text { Apoiar projetos de pesquisa, desenvolvimento tecnológico e inovação } \\
\text { (relacionados a novos produtos e processos) }\end{array}$ & $\begin{array}{l}\text { Vigente de } 2006 \text { a } \\
2008\end{array}$ \\
\hline $\begin{array}{l}\text { Linha Inovação } \\
\text { Produção }\end{array}$ & $\begin{array}{l}\text { Apoiar inovações incrementais (relacionados a produtos e processos), } \\
\text { formação de capacitações e ambientes inovadores, assim como para } \\
\text { criação, adequação e/ou expansão de capacidade para comercialização de } \\
\text { resultados de processos inovativos }\end{array}$ & $\begin{array}{l}\text { Vigente de 2008, sendo recriada } \\
\text { em }\end{array}$ \\
\hline $\begin{array}{l}\text { Programa de Apoio à } \\
\text { Engenharia } \\
\text { Automotiva }\end{array}$ & $\begin{array}{l}\text { Fortalecer áreas de engenharia de empresas vinculadas ao setor } \\
\text { automotivo, através de competências e desenvolvimento técnico }\end{array}$ & $\begin{array}{l}\text { Vigente de } 2007 \text { a } \\
2009\end{array}$ \\
\hline $\begin{array}{l}\text { Inovação } \\
\text { Tecnológica }\end{array}$ & $\begin{array}{l}\text { Apoiar projetos de pesquisa, desenvolvimento ou inovação (relacionados a } \\
\text { novos ou aprimorados produtos e processos, com significativo risco } \\
\text { tecnológico) }\end{array}$ & $\begin{array}{l}\text { Substitui } \\
\text { Inovação PD\&I, em } \\
2008\end{array}$ \\
\hline Capital Inovador & $\begin{array}{l}\text { Apoiar os esforços inovativos relacionados à infraestrutura física e ativos } \\
\text { tangíveis e intangíveis, assim como a parques tecnológicos e incubadoras }\end{array}$ & $\begin{array}{l}\text { Substitui a } \\
\text { Inovação Produção, em } \\
2008\end{array}$ \\
\hline $\begin{array}{l}\text { BNDES } \\
\text { Proengenharia }\end{array}$ & $\begin{array}{l}\text { Ampliação de financiamento para outros setores, além do automotivo, a } \\
\text { exemplo de bens de capital, aeronáutica, defesa, aeroespacial, nuclear, } \\
\text { assim como a cadeia de fornecedores das indústrias de petróleo e gás }\end{array}$ & $\begin{array}{l}\text { Substitui o Programa } \\
\text { de Apoio à Engenharia } \\
\text { Automotiva, em 2009 }\end{array}$ \\
\hline
\end{tabular}

Fonte: elaboração dos autores, com base em Barros e Pedro (2012).

Nota: *Pesquisa, Desenvolvimento e Inovação (PD\&I).

Todos esses meios de financiamento contribuíram significativamente para o estímulo a inovação na cadeia automotiva. Cabe fazer menção ao BNDES Proengenharia, que a partir da segunda metade da década de 2000 financiou vários projetos de empresas sistemistas e fabricantes de veículos instalados no país, contribuindo para elevar a competição entre companhias. Exemplos desses projetos estiveram ligados "[...] à reestilização de veículos, o desenvolvimento de novos motores para veículos pesados adequados às exigências da legislação ambiental, bem como a implantação, a ampliação e a modernização de centros de engenharia nas empresas produtoras de veículos e autopeças." (BARROS; PEDRO, 2012, p.119).

Neste contexto, observa-se que a partir dos programas e linhas de financiamentos destinados aos processos inovativos e tecnológicos da cadeia automotiva, o BNDES tem participado e contribuído para a manutenção e expansão da competitividade do setor. Casotti e Goldenstein (2008) destacam que as mudanças e substituições de alguns programas e linhas de financiamento do BNDES foram fundamentais para superar a concepção de financiamento e apoio destinados a projetos de engenharia para $o$ desenvolvimento de um veículo específico. A partir do Programa de Apoio à Engenharia Automotiva, o BNDES amplia sua concepção de apoio e financiamento para estimular e fortalecer os setores de engenharia e P\&D das empresas de veículos e autopeças como um todo e não apenas ao desenvolvimento de novos produtos e processos. Destarte, cabe ressaltar que "tais investimentos geram conhecimento local e têm grande potencial para gerar diferenciação para a indústria nacional. Com a globalização da economia, o capital intelectual passou a ser o principal fator de competitividade das empresas" (CASOTTI; GOLDENSTEIN, 2008, p. 184).

\subsection{Inovações recentes e novas rotas tecnológicas para o setor automotivo}

Embora o setor automotivo tenha passado por diversas mudanças em termos de design e acessórios (ar-condicionado, câmbio automático, direção hidráulica, air bags, equipamentos de som e dentre outros) ao longo do século XX e início do século XXI, a funcionalidade dos automóveis, movidos com gasolina e com propulsão à explosão interna, não sofreu grandes alterações ao longo do período. Entretanto, a existência de três dilemas básicos tende a influenciar um novo ciclo na produção e desenvolvimentos dos veículos automotores. Os dilemas compreendem fatores como: 1) motivações ambientais, em decorrência do processo de combustão com a utilização de derivados do petróleo, contribuindo para a elevação das 
emissões de gás carbônico na atmosfera; 2) preço do petróleo, os combustíveis de origem fósseis possuem elevado preço e somado a questão ambiental têm impulsionado a busca por alternativas à sua utilização e; 3) novos mercados, onde os mercados emergentes têm apresentado grande potencial de crescimento (CASOTTI; GOLDENSTEIN, 2008). Conforme destacado em seções anteriores, devido ao baixo poder aquisitivo da população em países emergentes, a aposta deve ser em automóveis cada vez mais compactos, baratos e com design sofisticado. Por conseguinte, essas características induzem a uma tendência para a elevação da eficiência, redução do consumo de combustível e a busca por novas alternativas para atender as perspectivas de mercado, conforme exposto na figura 2 abaixo.

Figura 2 - Dilema e tendência para o setor automotivo

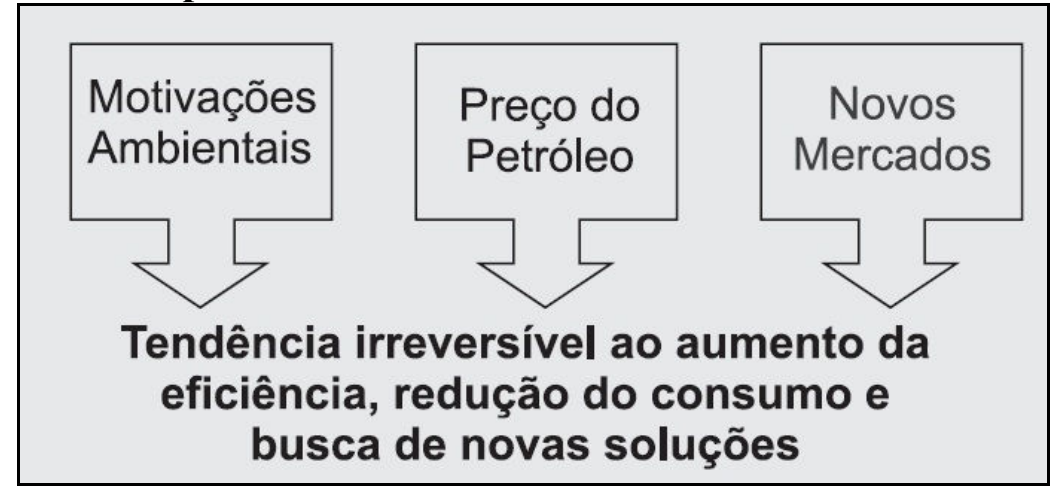

Fonte: Casotti e Goldenstein (2008)

Nesse contexto, novas tecnologias alternativas têm sido pesquisadas e desenvolvidas para enfrentar os três dilemas mencionados. Exemplo disso são as inovações incrementais no produto, novas fontes energéticas (com combustíveis renováveis ou sintéticos) e inovações radicais com a introdução de motores elétricos em detrimento de motores à explosão. Casotti e Goldensteins (2008) destacam o fato de que o contexto pelo qual o setor automotivo vem se configurando possibilita a coexistência de várias alternativas tecnológicas. No caso das inovações em fontes energéticas, mesmo com os avanços e disseminação do etanol e do biodiesel na frota de veículos e na matriz energética brasileira, investimentos tem sido realizado para o desenvolvimento de outros combustíveis renováveis, a exemplo do H-bio (combinação de diesel e óleos vegetais), o próprio óleo vegetal natural, combustíveis sintéticos (obtidos a partir da síntese de gás natural, carvão e biomassa) (CASOTTI; GOLDENSTEIN, 2008).

No que se refere às inovações radicais, especialmente vinculadas ao sistema propulsor, veículos híbrido elétrico já tem sido produzido nos mercados norte americano e japonês, e de forma incipiente no Brasil. Existem autores que apontam para a importância da produção de veículos híbridos, antes da difusão da tecnologia de veículos elétricos. Os argumentos se sustentam devido ao custo da bateria e do motor elétrico (sendo inferiores no veículo híbrido), assim como a baixa autonomia da bateria e da infraestrutura de recarga para veículos totalmente elétricos. Sendo assim, a produção de veículos híbridos combinaria tecnologias a combustão e elétrica. Dentre outras questões, a discussão que se coloca para a difusão de veículos elétricos está relacionada ao padrão de bateria, durabilidade, custo e infraestrutura de recarga (CASOTTI; GOLDENSTEIN, 2008; BARROS; PEDRO, 2012).

Modelos de veículos híbrido elétrico plug-in também têm sido desenvolvidos e lançados aos poucos em alguns mercados. Consiste na possibilidade de reabastecimento com conexão direta na rede elétrica doméstica, visando reduzir a necessidade de utilização de combustíveis fósseis, ainda utilizados na recarga de bateria em modelos híbridos elétricos (através do motor a explosão). Existem ainda pesquisas e testes relacionados a veículos híbridos hidráulicos, que combinam fontes de motor a combustão interna e uma bomba hidráulica para armazenamento de energia, visando à redução de custos na produção e manutenção. Por outro lado, Casotti e Goldensteins (2008) apontam que uma possível tecnologia de propulsão a prevalecer dentre tantas tentativas apresentadas no início dos anos 2000, e para substituir o carro movido a gasolina, seria o fuel cell, o sistema de pilhas de combustível. Neste caso, a energia não seria armazenada, mas gerada continuamente na célula a partir de uma reação química entre o hidrogênio e o oxigênio. Embora essa tecnologia indique para a viabilização da utilização dos veículos elétricos, 
ainda persistem outros entraves quanto ao custo de fabricação, durabilidade, potência e a produção do hidrogênio (a partir da combinação de outras substâncias, visto que não é encontrado no ambiente). Além da produção do hidrogênio, seria necessária a criação de infraestrutura para abastecimento do mesmo. Síntese dessa discussão encontra-se no quadro II, abaixo.

Quadro II - Aspectos inovativos para o setor automotivo

\begin{tabular}{|c|l|}
\hline Inovações & \multicolumn{1}{|c|}{ Principais aspectos } \\
\hline $\begin{array}{c}\text { Características dos } \\
\text { produtos }\end{array}$ & $\begin{array}{l}\text { Carros menores, mais baratos, mais eficientes e com redução tanto de } \\
\text { consumo quanto de emissão de gás carbônico }\end{array}$ \\
\cline { 2 - 2 } Fonte energética & $\begin{array}{l}\text { Novos combustíncín dos (etanol, biodiesel, HBIO, óleo vegetal natural, sintéticos } \\
\text { (gas-toliquids - GTL; coal-to-liquids - CTL; biomassto-liquids - BTL). }\end{array}$ \\
\hline Inovações radicais & $\begin{array}{l}\text { Alternativas tecnológicas ao motor a explosão interna (híbrido-elétrico, plug- } \\
\text { in, fuel-cell) }\end{array}$ \\
\hline
\end{tabular}

Fonte: adaptado pelos autores, a partir de Casotti e Goldenstein (2008)

Assim sendo, tanto a participação dos financiamentos do BNDES e o ambiente macroeconômico (política industrial, de ciência e tecnologia, de comércio, monetária e educacional) quanto à integração com fontes nacionais de tecnologia (institutos e centros de pesquisa, universidades e outros sistemas de apoio) fazem-se cada vez mais necessários para o estímulo ao desenvolvimento de inovações que envolvem um elevado risco e mudanças na trajetória tecnológica (KIM, 2005).

Cabe destacar que a discussão destas rotas tecnológicas para o setor automobilístico brasileiro ganham ênfase, especialmente, devido ao crescimento da economia e do mercado doméstico nos últimos anos, a ascensão da classe média e do salário mínimo real, assim como a tendência para estagnação de mercados desenvolvidos, o que abre espaço para o crescimento da participação dos países em desenvolvimento na produção de veículos (BARROS; PEDRO, 2012). A discussão das principais tendências e rotas tecnológicas vinculadas à inovação de produtos e processos na cadeia automotiva tanto confirma a importância de políticas públicas de financiamento para o desenvolvimento e estímulo à inovação do setor, quanto demanda aprimoramentos dos atuais meios de financiamento e a criação de novos.

\section{CONSIDERAÇÕES FINAIS}

O presente trabalho buscou apresentar uma discussão sobre a indústria automobilística, envolvendo a reestruturação produtiva e concorrencial, as inovações recentes e rotas tecnológicas para o setor automotivo, assim como destacar a importância do financiamento estatal brasileiro, especificamente dos programas e linhas de financiamento do Banco Nacional de Desenvolvimento Econômico e Social (BNDES) para impulso e desenvolvimento de inovações para o setor. Além disso, procurou-se apresentar uma revisão de literatura sobre o setor automotivo e as políticas industriais brasileiras, assim como uma caracterização dos principais aspectos do setor e políticas adotadas para estímulo a competitividade.

A partir da discussão realizada e dos dados coletados de produção de autoveículos, destacou-se a evolução da participação dos países emergentes na produção mundial, especialmente vinculado a saturação dos mercados desenvolvidos e a consequente internalização de grandes montadores multinacionais nos países emergentes. Considerando-se o conjunto de países emergentes selecionados (Argentina, Brasil, China Índia, México, Rússia, Tailândia e países do leste europeu) a participação na produção de autoveículos mundiais saiu de 18,9\% em 2002 para 48,6\% em 2016, configurando-se em um crescimento de $157 \%$. Isso indica o quanto os mercados emergentes têm ganhado importância na reestruturação produtiva mundial, onde a aposta para os próximos anos ainda continua sendo de crescimento. Entre as economias emergentes, China e Índia têm apresentado os melhores resultados na produção de autoveículos, onde o bom desempenho está relacionado a uma participação ativa do governo com estímulos para o setor, assim como ao padrão de produção em carros compactos e baratos, 
direcionados para o perfil de uma população de baixo poder aquisitivo e que, em muitos casos, nunca possuíram um automóvel. Esses países configuram-se como um dos maiores mercados consumidores em potencial para o setor automotivo.

As subsidiárias brasileiras também tem apostado no desenvolvimento de veículos mais compactos e econômicos. Durante o século XX, observa-se uma indústria voltada para montagem de partes e peças importadas, tentativas de nacionalização de peças e uma descontinuidade das políticas indústrias para o setor automotivo, com foco para a implantação da indústria pesada, especialmente após a década de 1960. $\mathrm{O}$ processo de abertura comercial intensificou a competitividade, devido à entrada de veículos importados, o país contou com a entrada de investimento direto externo de grandes montadoras multinacionais e recentemente tem-se configurado como um importante centro para fabricação e distribuição de autoveículos na América do Sul. As políticas industriais e financiamentos para estímulo à competitividade do setor, via desenvolvimento inovativo, apresentam-se como elemento estratégico.

Questões como a sustentabilidade ambiental na sociedade contemporânea, as modificações e tendências tecnológicas atrelado à concorrência inerente ao processo inovativo do setor automotivo são elementos que podem alterar significativamente toda a estrutura da indústria automobilística. Neste contexto, o estímulo a pesquisa e desenvolvimento continuam sendo essenciais para o potencial de novas tecnologias ligadas a eletromobilidade, hibridização, combustíveis alternativos e nanotecnologia. Esta última configura-se como uma oportunidade tecnológica que pode contribuir tanto para aperfeiçoamentos no produto (funcionalidade e design de peças) quanto em melhorias de processos.

Com o fortalecimento das empresas sistemistas dentro da cadeia automotiva, o processo de desenvolvimento de inovações para o setor tende a se ampliar além do escopo das empresas montadoras (matriz e filiais), abrindo espaço para as inovações oriundas de outras áreas, a exemplo das tecnologias de informação e comunicação. Investimentos em P\&D configura-se como elementos fundamentais para atender às novas rotas tecnológicas do setor, necessitando de políticas públicas direcionadas e de financiamentos governamentais para estímulo às inovações de longo prazo na indústria automotiva.

\section{REFERÊNCIAS}

ANFAVEA - ASSOCIAÇÃO NACIONAL DOS. FABRICANTES DE VEÍCULOS AUTOMOTORES. Estatísticas. 2017. Disponível em: <http://www.anfavea.com.br/estatisticas.html >. Acesso em: Acesso em: 20 abr. 2017.

BAHIA, Luiz Dias; DOMINGUES, Edson Paulo. Estrutura de inovações na indústria automobilística brasileira. (Texto para discussão n. 1472). Brasília: IPEA, 2010, p. 1-26.

BARROS, Daniel Chiari; PEDRO, Luciana Silvestre. O papel do BNDES no desenvolvimento do setor automotivo brasileiro. BNDES 60 anos - perspectivas setoriais. Brasília: BNDES, 2012, p. 98-139.

BATISTA JUNIOR, Paulo Nogueira. O consenso de Washington: a visão neoliberal dos problemas latino-americanos. São Paulo: Paz e Terra, 1994.

BNDES - BANCO NACIONAL DO DESENVOLVIMENTO. Plano Brasil Maior. BNDES.gov, 2016. Disponível em:

$<$ http://www.bndes.gov.br/SiteBNDES/bndes/bndes_pt/Hotsites/Relatorio_Anual_2011/Capitulos/atuaca o_institucional/o_bndes_politicas_publicas/plano_brasil_maior.html $>$. Acesso em: 10 ago. 2016.

BRASIL. MINISTÉRIO DO DESENVOLVIMENTO, INDÚSTRIA E COMÉRCIO EXTERIOR. Plano Brasil Maior. MDIC.gov, [2016]. Disponível em: <http://www.brasilmaior.gov.br/conteudo/128>. Acesso em: 25 ago. 2016.

CAPUTO, Ana Cláudia; MELO, Hildete Pereira de. A industrialização brasileira nos anos de 1950: uma análise da instrução 113 da SUMOC. Estudos Econômicos (São Paulo), v. 39, n. 3, p. 513-538, 2009. 
CARVALHO, Enéas Gonçalves de. Inovação tecnológica na indústria automobilística: características e evolução recente. Economia e Sociedade, p. 429-461, 2008.

CASOTTI, Bruna Pretti; GOLDENSTEIN, Marcelo. Panorama do setor automotivo: as mudanças estruturais da indústria e as perspectivas para o Brasil. BNDES Setorial, Rio de Janeiro, n. 28, p. 147$187,2008$.

CASSIOLATO, José Eduardo. Políticas de desenvolvimento industrial para o Brasil: Lições da experiência internacional. Econômica, v. 5, n. 2, p. 317-324, 2003.

CORONEL, Daniel Arruda; AZEVEDO, André Filipe Zagode; CAMPOS, Antônio Carvalho. Política industrial e desenvolvimento econômico: a reatualiação de um debate histórico. Revista de Economia Política, v. 34, n. 1, jan./mar. 2014, p. 103-119.

COSTA, Rodrigo Morem; HENKIN, Hélio. Estratégias competitivas e desempenho da indústria automobilística no Brasil. Economia e Sociedade, v. 25, n. 2, p. 457-487, 2016.

DE NEGRI, Fernanda et al. Determinantes da acumulação de conhecimento para inovação tecnológica nos setores industriais no Brasil - setor automotivo. Brasília: ABDI, 2008, 104 p.

EVANS, P. Estados e transformação industrial. In: EVANS, P. Autonomia e parceria: Estados e transformação industrial. Rio de Janeiro: Editora UFRJ, 2004, p. 27-47.

FREEMAN, Chris; SOETE, Luc. A produção em massa e os automóveis. In: . A economia da inovação industrial. São Paulo: Editora Unicamp, 2008. p. 237-276.

FURTADO, Celso. Deslocamento do centro dinâmico. In: Paulo: Companhia Editora Nacional, 2005, ed. 32, p. 203-212.

. Formação econômica do Brasil. São

FURTADO, J. Sistematização do debate sobre política industrial. Desenvolvimento em Debate - Política Industrial. BNDES, 2002, p. 133-153.

KIM, Linsu. Da imitação à inovação: a dinâmica do aprendizado tecnológico da Coréia. Campinas: Editora Unicamp, 2005.

LACERDA, Antônio Corrêa de et al. Economia brasileira. 4 ed. São Paulo: Saraiva, 2010.

MATTOS, C. Análise do Plano Brasil Maior. Brasília, Nota técnica da Câmara dos Deputados, 2013, p. 26. Disponível em: <http://www2.camara.leg.br/documentos-e-pesquisa/publicacoes/estnottec/areas-daconle/tema10/2013_7665_versao\%20para\%20publicacao.pdf>. Acesso em: 12 ago. 2016.

MAZZUCATO, M. Da ideologia da crise à divisão do trabalho inovador. In: MAZZUCATO, M. O estado empreendedor: desmascarando o mito do setor público vs. setor privado. ed. São Paulo: Portfolio-Penguin, 2014, p. 41-57.

MEZA, Maria Lúcia. Trabalho qualificado e competência: um estudo de caso da indústria automotiva paranaense. 2003. 217 f. Tese (Doutorado em Desenvolvimento Econômico) Universidade Federal do Paraná, Curitiba. 2003.

NELSON, R; WINTER, S. Forças geradoras e limitantes da concentração sob concorrência shumpeteriana. In: NELSON, R; WINTER, S. Uma teoria evolucionária da mudança econômica. São Paulo: Editora Uniamp, 1997, p. 443-469.

OICA - ORGANISATION INTERNATIONALE DES CONSTRUCTEURS D'AUTOMOBILES. Production Statistics. 2017. Disponível em: <http://www.oica.net/category/production-statistics/>. Acesso em: 18 abr. 2017. 